restricted to non-profit-making European technical and scientific societies the activities of which are connected with the field of corrosion or the protection of materials. Tho Foderation seeks to achieve its objects by convening joint European meetings for the discussion of subjects of general interest; by convening meetings of working parties for the discussion of specific problems; by the creation of working groups for investigating special problems; by the organization of study trips; and by other means. The General Secretariat of the Federation is managed jointly by the Dechema in Frankfurt a.M. and the Société de Chimie Industrielle in Paris.

The British Association of Corrosion Engineers was formed last year (see Nature, 183, 1779; 1959) generally to promote the dissemination of tochnical information about corrosion matters ; to develop the free interchange of information among members; and to promote such educational and other facilities as may be required for the establishment of corrosion engineering as a rocognized profession. Individual membership (two guineas a year) is open to everyone interested and associated with corrosion engineering. The address of the Honorary Secretary is 97 Old Brompton Road, London, S.W.7.

The British Hydromechanics Research Association

THE twelfth annual report of the British Hydromechanics Research Association covers the year October 1958-September 1959 , in which the membership increased by 14 to 89 ordinary and 104 associate members. Brief summaries are given of some of the research in progress, including the construction of a new apparatus for testing mechanical and radial-face seals, an attempt to explain the sealing mechanism of fabric-rubber seals for reciprocating shafts, and a study of the effects of internal leakage of energy from centrifugal pumps through neck rings. Careful tests with a modern design of « large fan showed that velocity measurements in a rectangular dischargeduct at equidistant points in the cross-section gave results $2 \cdot 7$ per cent or more too high. Work is also complete on model tests for the National Coal Board to study flow-conditions and determine pressure losses in gallery-type fan drift junctions and shaft insets, and experimental work has been completed on the influence of size distribution on the flowcharacteristics of liquid/solid mixtures, where the solid particles are larger than about 100 mesh. The National Physical Laboratory electronic simulator has been used to investigate surge problems associated with the design of the siphon draw-off tower for Tryweryn reservoir, and the possibilities of depriming a siphon while passing a high discharge were also examined. Results havo been obtained for the fatigue of four flexible high-pressure hoses, and work continued on a model valve for automatic control systems. As a result of tests on a model of the four tidal gates and diversion channel, and on another large model of one pair of gates for a new tidal outfall proposed by the Cheshire River Board for the River Birkett at Birkenhead, a silt deflector and other hydraulic improvernents have been added to the original design and gates calibrated as a means of measuring river flow.

Medical Research in France: the Paris Hospitals

French Science News (No. 1, 1960, January-March) includes a special article on medical research in the Paris hospitals, covering both the more or less autonomous organizations such as the Pasteur
Institute, the Cancer Institute, the National Blood Transfusion Centre, the Atomic Energy Commission at Saclay with the d'Orsay Hospital and laboratory and the research centres set up within the Hospitals of Public Assistance. These hospitals include about twenty research organizations which havo the advantage of being in intimate contact with the patient any time it is necessary. Some of these centres have been grouped since 1955 into the Claud Bernard Association, founded in June 1953, to facilitate the development of medical and biological research in these hospitals. The article outlines the organization and orientation of research in these various centres, including the leukæmia and blood disease research centre, the research centre for the medical application of isotopes, the allergy and immunology research centre, the renal insufficiency research centro, the centre of immuno-pathology, the biological research centre for new-born infants, the neurophysiology, the pharmacological, the experimontal surgory, and the cardiological research contres, the gerontological centre, the medical biochemistry research laboratory, the laboratory for medical biochemical research, the neurorespiratory revival centre of the clinic for infectious diseases, the clinic for medical and social rheumatology, the dietetic and human nutrition research unit, and the gastroenterological research centres, Saint-Antoine and Bichat Hospitals.

\section{Darwin's Notebooks on Transmutation of Species}

Is his "First Notebook", on transmutation of species, Darwin satisfied himself that it had occurred whon populations were isolated and no longer able to prevent variation that resulted from sexual reproduction, and is normally kept in check by breeding throughout the population. In this way varieties become split off from the species and eventually become species themselves, while old species become extinct, thereby increasing the separation between surviving species, many of which after being split into daughter species become genera. In his "Second Notebook", which represents his train of thought from the beginning of February until the first half of July 1838, Darwin was already concerned with the problem of expressing his views on paper and gave himself instructions for presenting his theory. Like the "First Notebook" (see Nature, 185, 580; 1960), the "Second Notebook" has been edited by Sir Gavin de Beer and issued with explanatory notes (Bullotin of the British Museum (Natural History). Historical Series. 2, No. 3: Darwin's Notebooks on Transmutation of Species. Part 2. (February to July 1838.) Pp. 75-118. (London: British Museum (Natural History), 1960.) 15s.). The "Second Notebook" not only describes Darwin's methods of presenting his theory but, incidentally, gives his views on slavery, education, and "the improvement of women".

\section{English Rural Life}

THE report of the Museum of English Rural Life for 1959 is, as usual, far more than a formal statement (pp. 22, 5 plates. Reading : Musoum of English Rural Life, The University, 1960. 1s.). This Museum in the University of Reading is still engaged in its threefold task of collecting objects from the countryside, accumulating a library of documentary information and carrying out research on the material acquired. The Museum is, however, concerned that, owing to lack of financial support, it is not possible 